\title{
Efficacy of Chemotherapy Combinations in Metastatic Castration-Resistant Prostate Cancer Patients - Do Homologous Recombination Deficiency Affect the Outcomes?
}

\author{
(1) Emre Yekedüz, (1) Güngör Utkan, (1) Yüksel Ürün \\ Ankara University Faculty of Medicine, Department of Medical Oncology, Ankara, Turkey
}

\begin{abstract}
Homologous recombination (HR) is a major repair mechanism of DNA damage. Platin-based agents are known to be more effective in patients with impaired HR mechanism. Previous studies combined platin compounds with docetaxel, but most of these studies did not perform subgroup analysis for HR-deficient patients. Aggressive variant prostate cancer (AVPC) is considered more susceptible to carboplatin. Furthermore, prostate cancers with a higher rate of small cell or anaplastic carcinoma components are more susceptible to carboplatin plus etoposide. We thought that the effect of cabazitaxel plus carboplatin on the progression-free survival might be related to carboplatin alone. In a study that evaluated the effect of cabazitaxel plus carboplatin, the proportion of AVPC patients was higher in the combination group than in the cabazitaxel group. Additionally, the combination of cabazitaxel and carboplatin led to increased toxicity.

Keywords: Chemotherapy, homologous-recombination deficiency, prostate cancer
\end{abstract}

Several clinical trials investigated the efficacy of combination chemotherapy for metastatic castration-resistant prostate cancer (mCRPC). In most of these trials, combination regimens are not superior to single-agent regimen (e.g., docetaxel or cabazitaxel). Hence, docetaxel and cabazitaxel (especially in the second-line setting) are the standard chemotherapeutic agents for mCRPC $(1,2)$.

Homologous recombination (HR) is a major repair mechanism of DNA damage. In a previous study, 20\%-25\% of CRPC patients had a defect in the HR repair genes (3). Particularly, BRCA2 mutations were more frequent than mutations of other HR repair genes $(4,5)$. Platin-based agents are known to be more effective in patients with impaired HR mechanism. In previous studies, platin compounds were combined with docetaxel, but most of these studies did not perform subgroup analysis for patients with HR repair mechanism deficiency. However, a prospective analysis of $\mathrm{MCRPC}$ patients with BRCA2 mutations revealed the efficacy of docetaxel plus carboplatin (6).

Aggressive variant prostate cancer (AVPC) is defined based on the clinicopathological or molecular features of prostate cancer. Prostate cancer characterized by small cell or anaplastic carcinoma morphology and atypical features or mutations of TP53, PTEN, or RB1 genes are considered as AVPC (7). Furthermore, BRCA mutation carriers have more aggressive prostate cancer (8). Therefore, mutations of BRCA and other DNA repair genes were seen commonly among patients with AVPC (9). Prostate cancers with these aspects are considered more susceptible to carboplatin (10). Furthermore, prostate cancers with a higher rate of small cell or anaplastic carcinoma components are more susceptible to carboplatin plus etoposide (11). In patients with mCRPC, $H R$ gene defects (e.g., PTEN gene defect) cause aggressive prostate cancer and taxane resistance (12).

Corn et al. (13) showed that cabazitaxel plus carboplatin improved the survival outcome in patients with MCRPC. In this study, the effect of cabazitaxel plus carboplatin on the progression-free survival might be related to carboplatin alone. In this study, the proportion of patients with AVPC was also higher in the combination group than in the cabazitaxel group (the AVPCclinicopathological criteria was $56 \%$ versus $52 \%$ and the AVPCmolecular signature was $52 \%$ versus $36 \%$ in the cabazitaxel and cabazitaxel plus carboplatin groups, respectively). Furthermore, the authors mentioned that the benefit from the combination therapy was greater in the AVPC group than in the non-AVPC group. Consequently, the results were consistent with the effect

Cite this article as: Yekedüz E, Utkan G, Ürün Y. Efficacy of Chemotherapy Combinations in Metastatic Castration-resistant Prostate Cancer Patients - Do Homologous Recombination Deficiency Affect the Outcomes? Bull Urooncol 2020;19(4):175-176

Address for Correspondence: Emre Yekedüz, Ankara University Faculty of Medicine, Department of Medical Oncology, Ankara, Turkey Phone: +90 3125957112 E-mail: dremre1988@gmail.com ORCID-ID: orcid.org/0000-0001-6819-5930 Received: 15.01.2020 Accepted: 03.03.2020 
of carboplatin in AVPC. Additionally, combination of cabazitaxel and carboplatin led to increased toxicity in this trial.

To our knowledge, no clinical trial has compared the effect of carboplatin as a single agent with docetaxel or cabazitaxel among patients with $H R$ gene mutations. An ongoing phase 2 trial compares the effectiveness of carboplatin and docetaxel among patients with BRCA1, BRCA2, or PALB2 mutations (NCT04038502). The results of this trial will clearly present the effect of carboplatin alone versus docetaxel among patients with who have $H R$ gene mutations.

\section{Acknowledgements}

Publication: The results of the study were not published in full or in part in form of abstracts.

Contribution: There is not any contributors who may not be listed as authors.

Conflict of Interest: No conflict of interest was declared by the authors.

Financial Disclosure: The authors declared that this study received no financial support.

\section{Ethics}

Peer-review: Externally peer-reviewed.

\section{Authorship Contributions}

Concept: E.Y., G.U., Y.Ü., Design: E.Y., G.U., Y.Ü., Data Collection and Processing: E.Y., G.U., Y.Ü., Analysis and Interpretation: E.Y., G.U., Y.Ü., Literature Search: E.Y., G.U., Y.Ü., Writing: E.Y., G.U., Y.Ü.

\section{References}

1. Eisenberger $M$, Hardy-Bessard AC, Kim CS, et al. Phase III Study Comparing a Reduced Dose of Cabazitaxel $(20 \mathrm{mg} / \mathrm{m}(2))$ and the Currently Approved Dose $(25 \mathrm{mg} / \mathrm{m}(2))$ in Postdocetaxel Patients With Metastatic Castration-Resistant Prostate Cancer-PROSELICA. I Clin Oncol 2017;35:3198-3206.
2. Tannock IF, de Wit R, Berry WR, et al. Docetaxel plus prednisone or mitoxantrone plus prednisone for advanced prostate cancer. $\mathrm{N}$ Engl J Med 2004;351:1502-1512.

3. Christenson ES, Antonarakis ES. PARP inhibitors for homologous recombination-deficient prostate cancer. Expert Opin Emerg Drugs 2018;23:123-133.

4. Oh M, Alkhushaym N, Fallatah $\mathrm{S}$, et al. The association of BRCA1 and BRCA2 mutations with prostate cancer risk, frequency, and mortality: A meta-analysis. Prostate 2019;79:880-895.

5. Nombela P, Lozano R, Aytes A, et al. BRCA2 and Other DDR Genes in Prostate Cancer. Cancers (Basel) 2019;11:352.

6. Pomerantz MM, Spisak S, Jia L, et al. The association between germline BRCA2 variants and sensitivity to platinum-based chemotherapy among men with metastatic prostate cancer. Cancer 2017; 123:3532-3539.

7. Tsaur I, Heidegger I, Kretschmer A, et al. Aggressive variants of prostate cancer - Are we ready to apply specific treatment right now? Cancer Treat Rev 2019;75:20-26.

8. Tryggvadottir L, Vidarsdottir L, Thorgeirsson T, et al. Prostate cancer progression and survival in BRCA2 mutation carriers. I Natl Cancer Inst 2007;99:929-935.

9. Chedgy EC, Vandekerkhove G, Herberts C, et al. Biallelic tumour suppressor loss and DNA repair defects in de novo small-cell prostate carcinoma. J Pathol 2018;246:244-253.

10. Beltran $\mathrm{H}$, Tomlins S, Aparicio A, et al. Aggressive variants of castrationresistant prostate cancer. Clin Cancer Res 2014;20:2846-2850.

11. Aparicio AM, Harzstark AL, Corn PG, et al. Platinum-based chemotherapy for variant castrate-resistant prostate cancer. Clin Cancer Res 2013;19:3621-3630.

12. Bumbaca B, Li W. Taxane resistance in castration-resistant prostate cancer: mechanisms and therapeutic strategies. Acta Pharm Sin B 2018;8:518-529.

13. Corn PG, Heath El, Zurita A, et al. Cabazitaxel plus carboplatin for the treatment of men with metastatic castration-resistant prostate cancers: a randomised, open-label, phase 1-2 trial. Lancet Oncol 2019;20:1432-1443. 